Article

\title{
Tracking of Physical Activity, Sport Participation, and Sedentary Behaviors over Four Years of High School
}

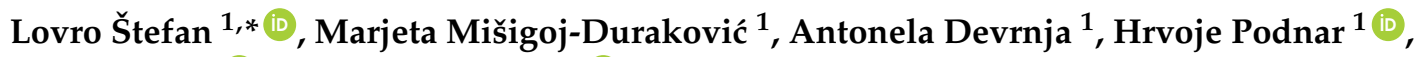 \\ Vilko Petrić 2 (1) and Maroje Sorić ${ }^{1,3}$ (1) \\ 1 Faculty of Kinesiology, University of Zagreb, Horvaćanski zavoj 15, 10000 Zagreb, Croatia; \\ marjeta.misigoj-durakovic@kif.hr (M.M.-D.); antonela.devrnja@kif.hr (A.D.); hrvoje.podnar@kif.hr (H.P.); \\ maroje.soric@kif.hr (M.S.) \\ 2 The Faculty of Teacher Education, University of Rijeka, 51000 Rijeka, Croatia; vilko.petric@uniri.hr \\ 3 Faculty of Sport, University of Ljubljana, 1000 Ljubljana, Slovenia \\ * Correspondence: lovro.stefan1510@gmail.com; Tel.: +385-09891-77-060
}

Received: 4 August 2018; Accepted: 30 August 2018; Published: 31 August 2018

\begin{abstract}
Background: The aim of the present study was to investigate the extent of tracking of physical activity (PA), sports participation (SP), and sedentary behaviors (SB) over four years of high school education among the Croatian Physical Activity in Adolescence Longitudinal Study (CRO-PALS) cohort. Methods: In this investigation, participants were 844 high school students (15.6 years at baseline; $49 \%$ girls). The SHAPES questionnaire was used to assess PA, SP, and SB at ages 15, 16, 17, and 18 and tracking was assessed using generalized estimating equations. Results: Tracking coefficients for PA were similar in both sexes, ranged from 0.49 to 0.61 , and indicated moderate tracking, while the tracking of SB tended to be somewhat higher over the four years of follow-up ( $\beta=0.60-0.72$ ). Youth that participated in sports at baseline had a 16 to 28 times higher odds of continued participation at follow-up, depending on the type of sport and gender. Finally, both low physical activity and high screen time showed strong tracking in both genders. Conclusion: PA and SB tracked moderately between ages 15 and 18. Moreover, the strong tracking of low PA and high screen time indicates that the detection of these risk factors at the beginning of high school should be advocated.
\end{abstract}

Keywords: longitudinal analysis; adolescence; sitting-time; physical inactivity; sustainability

\section{Introduction}

Physical inactivity is considered to be one of the most important public health concerns globally [1]. More recently, sedentary behavior (SB) has also been linked with an increased risk of mortality, independent of leisure-time physical activity (PA) [2]. In children, both low PA and high SB independently relate to adverse health outcomes $[3,4]$. Therefore, the World Health Organization recommends that children aged 5-17 years should accumulate at least $60 \mathrm{~min}$ of physical activity per day [1]. On the other hand, recent global studies have shown that this volume of PA is not achieved by the majority of contemporary youth, with the prevalence of inactivity rising with age [5]. Studies among school-going youth have consistently documented a steady decline in PA and an increase in SB throughout childhood [6-8]. The largest decline in PA has been spotted around the transition from primary to high school [9].

PA occurs in several domains, such as occupation, household, transportation, and leisure-time, which isthe one that contributes the most to total PA volume in children and adolescents [10]. 
The leisure-time domain has three aspects: mode (team sports, individual sports, organized but noncompetitive sports, and non-organized PA), setting (school, club, and neighborhood setting), and type (specific sports, such as swimming and volleyball) [11]. During teenage years, most of the leisure-time PA is organized and takes the form of sport activity. It has been shown that the number of leisure-time sport activities is positively associated with leisure-time PA, i.e., a higher number of sport activities that adolescents participated in was associated with a higher volume of leisure-time PA [12]. The same study also showed that the average weekly frequency of sport activities was 3.2 for boys and 2.8 for girls at the age of 17, yet girls engaged in a greater number of different sport activities than boys [12]. Longitudinal studies have shown that sport participation is the highest between ages 11-13, while after that period, it declines steadily throughout mid and late adolescence $[13,14]$. The decline is driven by a number of factors, such as lack of time and lack of support from families [15] and a shift towards academic achievements [16].

Given the importance of lifelong PA for health, interventions that promote physical activity and reduce sedentary behavior are one of the cornerstones of non-communicable disease prevention in children. If such interventions are to be effective in the long-term, the stability of PA and SB over time is assumed, i.e., these behaviors are expected to track well. Tracking is most often defined as: (1) "a tendency of individuals to maintain their rank within a certain group over a period of time" [17] and (2) "the ability to predict future observations based on earlier values" [18]. The most recent systematic reviews have documented weak to moderate tracking of PA and moderate tracking of SB, with the results being strongly dependent on age and the follow-up period $[19,20]$. Lower tracking was generally found with increasing follow-up interval [19]. Still, studies during late adolescence are scarce and the follow-up period studied has often been short, especially for SB. Furthermore, SB has usually been assessed through screen-time (ST), which represents just one domain of SB [21]. Finally, to the best of our knowledge, no study has simultaneously investigated the tracking of PA and SB in high-school-aged youth.

Therefore, the purpose of the present study was to investigate the extent of tracking of PA, sport participation (SP), and SB over four years of high school education.

\section{Materials and Methods}

\subsection{Study Participants}

The current study is part of the Croatian Physical Activity in Adolescence Longitudinal Study (CRO-PALS), an observational, longitudinal study that investigated behaviors of adolescents in the city of Zagreb (Croatia) throughout the four years of high school education. The sample size estimation and selection for the CRO-PALS study has been reported in detail elsewhere [22]. Briefly, a stratified two-stage random sampling procedure was employed to select an adequately large representative sample of urban adolescents. After having stratified all 86 secondary schools in the Zagreb area by type, grammar schools/vocational schools/private schools, 13 public (eight vocational and five grammar schools), and one private school (grammar school) were selected at the first stage of random selection, based on the share of different types of schools and the approximate number of eligible students per school of 150. All the invited schools agreed to participate, and during the second stage of randomization, half of the first grade classes in each school were randomly selected. Finally, all 1408 students enrolled in the chosen classes were contacted and 903 decided to join the study (response rate $=64 \%$ ). To check for possible selection bias, we compared participants to non-participants regarding the body-mass index (BMI), sum of four skinfolds (S4SF), and physical fitness (sit-ups and shuttle-run test). No significant differences between the two groups were found in any of the characteristics $(p=0.21-0.34)$.

All measurements were performed yearly in the period 2014-2017, during April and May, thus totaling four assessments. Prior to the study, all participants and their parents had signed an informed written consent and all the procedures were in accordance of the Declaration of Helsinki. 
The study was approved by the Institutional Review Board of the Faculty of Kinesiology, University of Zagreb, Croatia (No: 1009-2014).

\subsection{Physical Activity Assessment}

To assess PA and SB, we used a computerized version of the School Health Action, Planning and Evaluation System (SHAPES) questionnaire [23]. The validity and reliability of the SHAPES questionnaire for assessing PA and SB in primary and high school children has been investigated and the results were comparable to other PA questionnaires commonly used in this age group [23]. The questionnaire includes two items requesting a seven-day recall of moderate intensity PA (MPA) and vigorous intensity PA (VPA). VPA was defined as "jogging, team sports, fast dancing, jump-rope, and any other physical activity that markedly increased your heart rate and made you breathe hard and sweat", while MPA was defined as "lower intensity physical activities such as walking, riding a bike, and recreational swimming". Participants were instructed to specify the number of hours $(0-4 \mathrm{~h})$ and minutes in 15-min increments (0-45 $\mathrm{min})$ that MPA and VPA were performed for each day of the previous seven days. For all days at which $>4 \mathrm{~h}$ of MPA or VPA was reported, the duration of $4: 15 \mathrm{~h}$ was assumed (of note, such days constitute around $1 \%$ of the total days). Weekly duration of time spent in MPA and VPA was calculated by summing the responses for each of the seven days recalled. Physical activity energy expenditure (PAEE) was calculated as proposed by Wong et al. [23], assuming an average intensity of four METs for MPA and seven METs for VPA.

\subsection{Sedentary Behavior Assessment}

SBs were also examined by the SHAPES questionnaire, through two items examining time spent in pre-specified SBs on an average school day and on a typical weekend day. Sedentary time was examined through seven different groups of behaviors: (1) playing computer/video games, (2) television viewing, (3) browsing the internet (excluding school-work), (4) homework and studying, (5) listening to music, (6) reading for leisure (excluding school-work), and (7) playing instruments. As for PA, responses were provided by indicating the number of hours and minutes in 15-min increments [23]. We summed all seven SB domains to get the total sedentary time (TSB) and further subdivided SB activities into three categories: (1) screen-time (ST) (playing computer games, TV viewing, browsing the internet), (2) doing homework and studying, and (3) other SB activities (i.e., listening to music, reading, playing instruments). As schooldays and weekends were examined separately, the average daily time spent in particular SB was calculated as follows:

TSB, ST, studying and other SB activities $=[($ school day $\times 5)+($ weekend $\times 2)] / 7$.

\subsection{Sport Participation Assessment}

The original SHAPES questionnaire was supplemented with two YES/NO questions inquiring about regular participation in organized sports in school, as well as outside of the school. For participants who stated that they participate in organized sport, a comprehensive list of sport activities was offered, and participants identified all sports they participated in on a regular basis. Finally, a question about the weekly duration of sport activities (in 1-h increments) was also included.

\subsection{Data Analysis}

Tracking of PA and SB was assessed using generalized estimating equations (GEE), separate for each PA measure and each SB domain assessed. Specifically, to describe the extent of tracking of both PA and SB, we used the stability coefficient derived from the GEE analysis. When calculating a stability coefficient, the value of the baseline measurement was regressed on the entire longitudinal development of that variable from the second to the fourth measurement. The unique obtained regression (beta) coefficient is called the stability coefficient [24]. This coefficient ranges from 0 to 1 , with 1 indicating perfect tracking and 0 indicating no tracking. 
On the other hand, to evaluate the tracking of SP and behavioral risk factors (low PA and high screen time), we used odds ratios (ORs) derived from the GEE analysis. To track high physical activity ( $>75$ percentile), low physical activity ( $<25$ percentile), low screen time $(<25$ percentile), and high screen time ( $>75$ percentile), we used binary regression analysis in GEE. Participants were grouped according to the sex-specific quartiles of PAEE and ST. Odds ratios with $95 \%$ confidence intervals (OR; $95 \% \mathrm{CI}$ ) were calculated by GEE to determine the odds of remaining in a certain group compared with the baseline group position. The working correlation matrix was set to exchangeable in all analyses, i.e., the same within-subject correlation between each time point was assumed. Two-sided $p$-values were used and significance was set at $\alpha<0.05$. All the analyses were calculated in Statistical Packages for Social Sciences v.23 (SPSS, Chicago, IL, United States).

\section{Results}

The analyses in this study were based on 844 participants with data on PA, SP, and SB. Of these, $614(73 \%)$ were present at all four assessments, $150(18 \%)$ had three measurements, $44(5 \%)$ two measurements, and $36(4 \%)$ presented at only one occasion. The number of children involved dropped slightly during the study period. At first assessment, 843 children completed all the measurements (428 boys and 415 girls; $51.0 \% / 49.0 \%$ ); in second grade, there were 821 children present (413 boys and 408 girls; $50.3 \% / 49.7 \%$ ); that fell to 774 at the third year (394 boys and 380 girls; $51.0 \% / 49.0 \%$ ); and ended with 721 at the final, fourth, assessment (356 boys and 365 girls; $49.4 \% / 50.6 \%$ ). Basic characteristics of participants are presented in Table 1.

Table 1. Basic characteristics of the participants at baseline (first grade of high school), stratified by gender.

\begin{tabular}{lcc}
\hline \multicolumn{1}{c}{ Basic Descriptive Variables } & Boys $(\mathbf{N}=\mathbf{4 2 9})$ & Girls $(\mathbf{N}=\mathbf{4 1 5})$ \\
\hline Age (years) & $15.7(0.4)$ & $15.6(0.4)$ \\
Biological age (years from PHV) & $1.9(0.7)$ & $2.0(0.4)$ \\
Body-mass index $\left(\mathrm{kg} / \mathrm{m}^{2}\right)$ & $21.9(3.6)$ & $21.4(3.1)$ \\
Sum of 4 skinfolds * $(\mathrm{mm})$ & $37.3(18.9)$ & $50.0(16.2)$ \\
PAEE (kcal/kg/day) & $11.2(7.0)$ & $9.0(6.1)$ \\
Screen time (min/week) & $282.8(165.3)$ & $240.7(147.4)$ \\
\hline
\end{tabular}

* Sum of triceps, subscapular, suprailiac, and calf skinfold; PHV = peak height velocity; PAEE = physical activity energy expenditure.

Average durations of PA and various SB activities over four years of high school are depicted in Figure 1. The pattern of change in PA was similar in both genders and for both MPA and VPA. The average duration of PA was stable in the first two years, and dropped progressively afterwards. Conversely, the patterns of change in various SBs were not uniform across genders, with similar average values over all four years in girls, and a noticeable decrease between the first and fourth grade in boys.

Table 2 shows stability coefficients for PA and SB derived from GEE. In general, stability coefficients were almost identical in both sexes and indicate moderate tracking of PA and moderate to strong tracking of SB. Specifically, stability coefficients for PA ranged between 0.49-0.61 and were somewhat higher for VPA compared to MPA. The corresponding coefficients for SB were $0.60-0.72$ in boys and $0.60-0.70$ in girls. 
PAEE (kcal/kg/day)

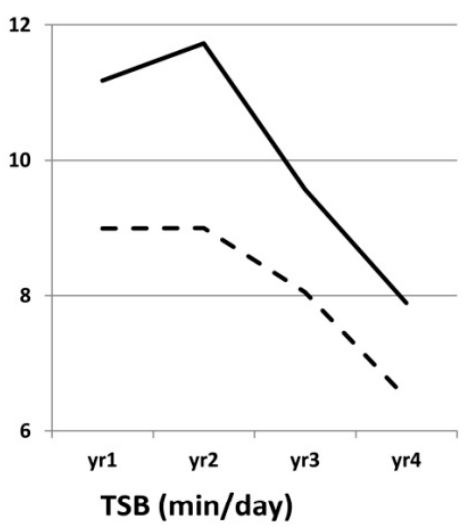

MPA (min/day)

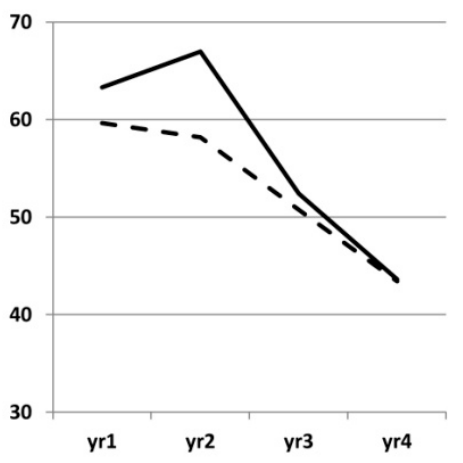

VPA (min/day)

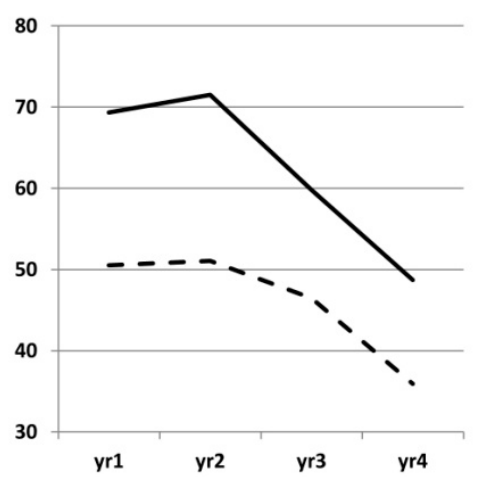

ST (min/day)

Studying ( $\mathrm{min} /$ day)

Other SBs (min/day)
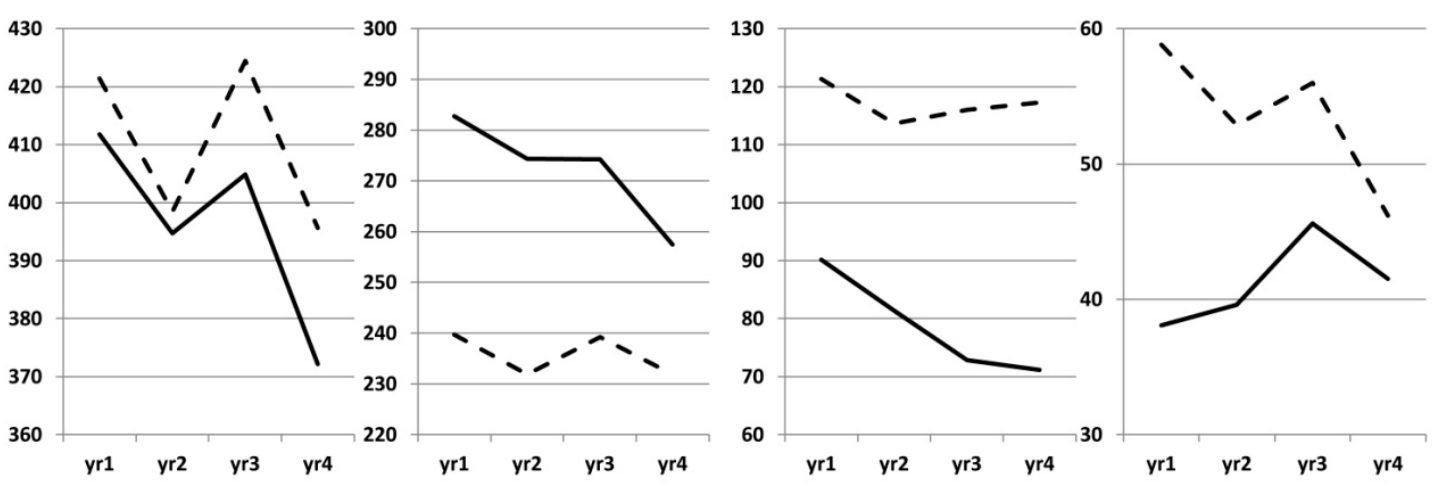

Figure 1. Average values of physical activity and sedentary behavior variables over four years of follow-up, in boys (- $)$ and girls (----).

Table 2. Stability coefficients for physical activity and sedentary behavior, stratified by gender.

\begin{tabular}{cccccccc}
\hline Study Variables & \multicolumn{3}{c}{ Boys (N = 429) } & \multicolumn{3}{c}{ Girls (N = 415) } \\
\hline & Tracking Coefficient & $\mathbf{9 5 \%}$ CI & $p$ & Tracking Coefficient & $\mathbf{9 5 \%}$ CI & $p$ \\
\hline \multicolumn{7}{c}{ Physical activity } \\
VPA & 0.61 & 0.54 to 0.67 & $<0.001$ & 0.59 & 0.52 to 0.66 & $<0.001$ \\
MPA & 0.49 & 0.43 to 0.56 & $<0.001$ & 0.53 & 0.45 to 0.60 & $<0.001$ \\
PAEE & 0.57 & 0.51 to 0.63 & $<0.001$ & 0.59 & 0.52 to 0.67 & $<0.001$ \\
\hline \multicolumn{7}{c}{ Sedentary behaviors } \\
TSB & 0.63 & 0.57 to 0.69 & $<0.001$ & 0.60 & 0.53 to 0.66 & $<0.001$ \\
ST & 0.60 & 0.54 to 0.66 & $<0.001$ & 0.64 & 0.58 to 0.70 & $<0.001$ \\
Studying & 0.66 & 0.61 to 0.72 & $<0.001$ & 0.70 & 0.65 to 0.76 & $<0.001$ \\
Other SB & 0.72 & 0.64 to 0.81 & $<0.001$ & 0.63 & 0.55 to 0.71 & $<0.001$ \\
\hline
\end{tabular}

VPA-vigorous physical activity; MPA-moderate physical activity, PAEE-physical activity energy expenditure; TSB-total sedentary behavior; ST-screen-time; Other SBs include reading for fun, listening to music, and playing an instrument.

Figure 2/Table 3 illustrates the tracking of risky behaviors, i.e., low physical activity and high screen time. The stability of high and low PA, as well as high and low ST, was very similar. About half of the children remained in both high and low groups between any two successive yearly assessments. The least active boys and girls at year 1 had $13.3(\mathrm{CI}=9.8-18.1)$ and $11.6(\mathrm{CI}=8.58-15.81)$ more odds of remaining in the least active quartile throughout the four years of high school compared to their peers, respectively. Similarly, boys with the highest PA level at year 1 were 12.9 (9.4-17.9), while girls were 14.9 (10.7-20.7) times more likely to remain in the most active group throughout high school. Boys who were in the highest screen-time quartile in first grade had $13.9(\mathrm{CI}=8.7-16.3)$ more odds of reporting high screen time throughout four years of high school, while the corresponding odds in 
girls were $15.5(\mathrm{CI}=11.2-21.5)$. On the other side of the spectrum, the odds of persistently being in the lowest screen-time quartile amounted to $12.6(\mathrm{CI}=9.1-17.4)$ in boys and $12.1(\mathrm{CI}=8.8-16.5)$ in girls who reported the lowest screen time at baseline.
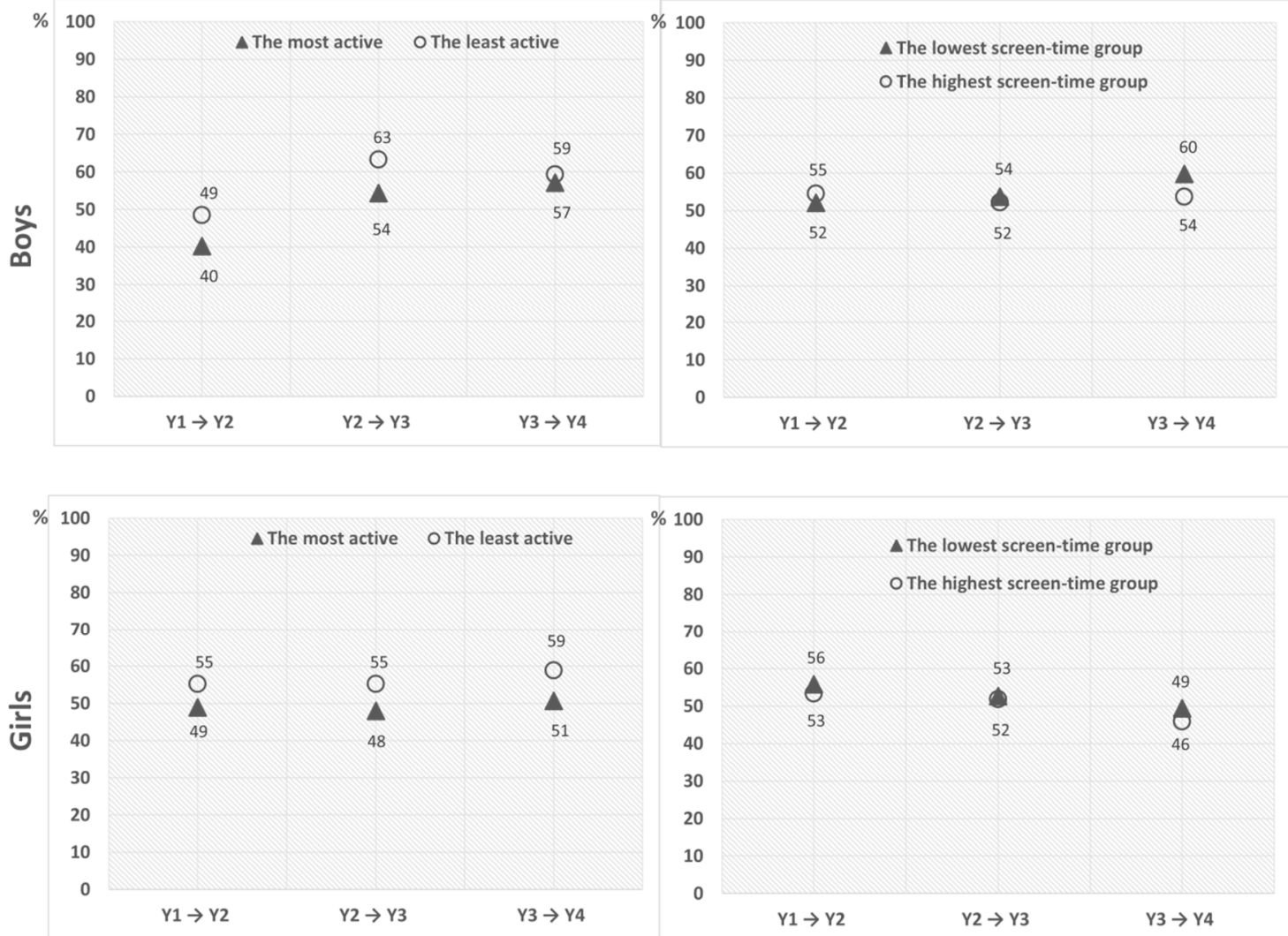

Figure 2. Tracking of low and high physical activity (the lowest and the highest sex-specific quartile of weekly physical activity energy expenditure, respectively), and low and high screen time (the lowest and the highest sex-specific quartile of weekly screen time, respectively), over four years of high school, stratified by gender. The numbers indicate the percentage of participants that remained in a specific group between two successive waves of assessment.

Table 3. Tracking of low and high physical activity (the lowest and the highest sex-specific quartile of weekly physical activity energy expenditure, respectively), and low and high screen time (the lowest and the highest sex-specific quartile of weekly screen time, respectively), over four years of high school, stratified by gender. The numbers indicate the percentage of participants that remained in a specific group between two successive waves of assessment.

\begin{tabular}{lcccccc}
\hline & \multicolumn{3}{c}{ Boys } & \multicolumn{3}{c}{ Girls } \\
\hline & $\mathbf{Y 1} \rightarrow \mathbf{Y 2}$ & $\mathbf{Y 2} \rightarrow \mathbf{Y 3}$ & $\mathbf{Y 3} \rightarrow \mathbf{Y 4}$ & $\mathbf{Y 1} \rightarrow \mathbf{Y 2}$ & $\mathbf{Y 2} \rightarrow \mathbf{Y 3}$ & $\mathbf{Y 3} \rightarrow \mathbf{Y 4}$ \\
\hline Physical activity & $\%$ & $\%$ & $\%$ & $\%$ & $\%$ & $\%$ \\
The lowest quartile & 40 & 54 & 57 & 55 & 55 & 59 \\
The highest quartile & 49 & 63 & 59 & 49 & 48 & 51 \\
\hline Screen time & & & & & & \\
The lowest quartile & 54 & 52 & 53 & 56 & 53 & 49 \\
The highest quartile & 51 & 53 & 59 & 52 & 51 & 46 \\
\hline
\end{tabular}

The numbers indicate the percentage of participants that remained in a specific category between two successive waves of assessment. 
The number of youth engaged in school and out-of-school sports further classified by the type of sport (individual vs. team sports) over four years of follow-up is presented in Figures 3 and 4/Table 4. At baseline, $54 \%$ of boys and $44 \%$ of girls participated in any kind of sport and the rates of participation decreased steadily afterwards. Boys who participated in school and out-of-school sports in first grade were $18.3(\mathrm{CI}=12.9-25.5)$ and $24.0(\mathrm{CI}=16.8-34.3)$ times more likely to continue participating over the follow up-period, respectively. The analogous odds in girls were very similar and amounted to $18.7(\mathrm{CI}=12.9-25.5)$ and $28.6(\mathrm{CI}=19.5-42.1)$. The tracking of sport participation was higher for team sports compared to individual sports in boys, but the opposite was true in girls. Specifically, boys who participated in team sports in first grade were $27.2(\mathrm{CI}=18.3-40.4)$ times more likely to continue participating over the follow-up period, while the corresponding odds for individual sports were $20.4(\mathrm{CI}=14.3-29.0)$. On the other hand, girls who participated in team sports in first grade were $15.9(\mathrm{CI}=10.1-24.9)$ times more likely to continue participating over the follow-up period, while the equivalent odds for individual sports were $23.6(\mathrm{CI}=15.6-35.6)$. The most popular sports were soccer, basketball, dancing, combat sports, volleyball, athletics, and swimming (data not presented).

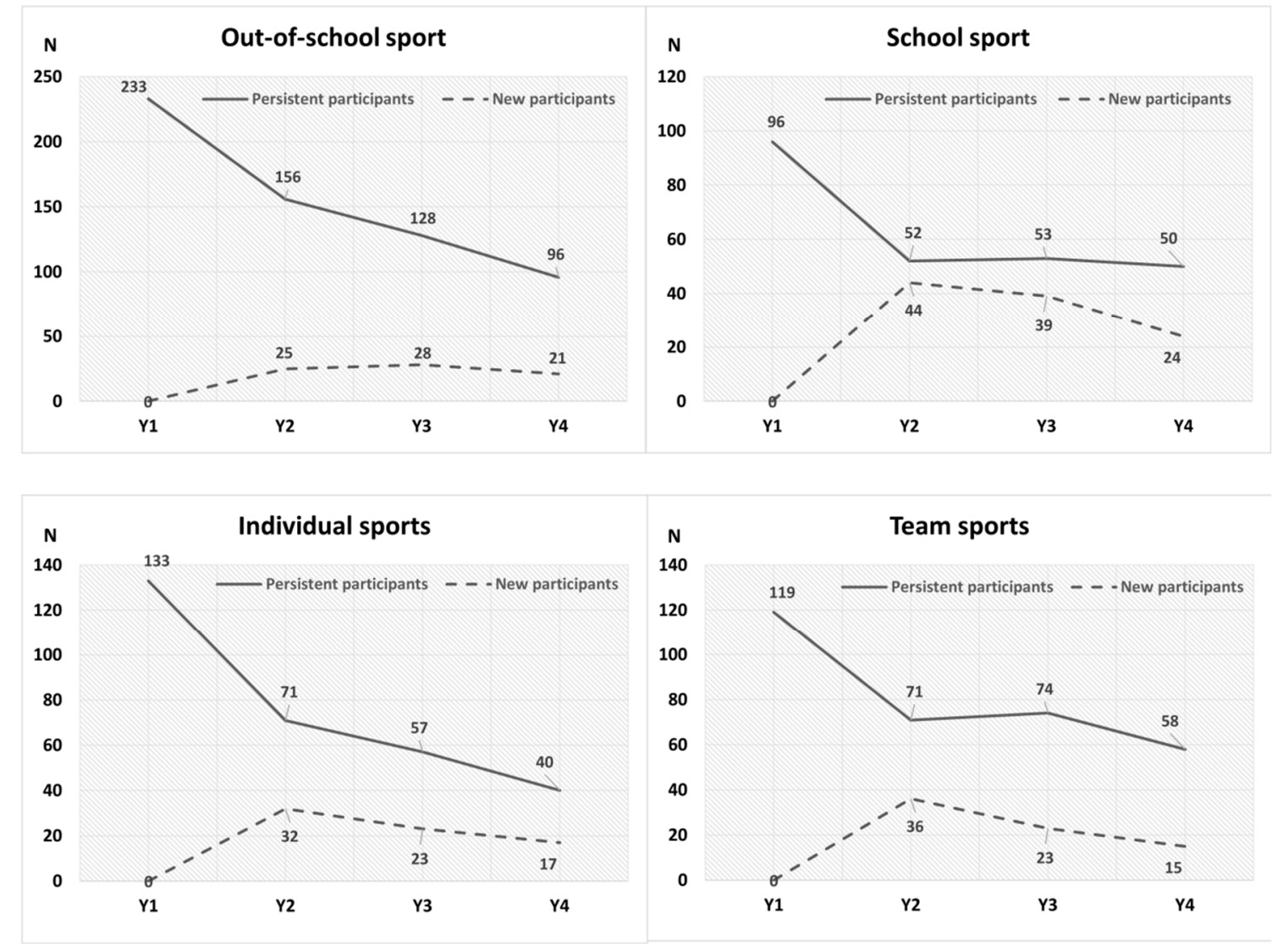

Figure 3. Persistence of sport participation over four years of high school in boys, stratified by school and out-of-school sport and by sport type (individual vs. team sports). The numbers show the frequency of children that participated in regular sport activities during a specific year. Solid line denotes participants who persistently participate in regular organized sport (Persistent participants) and dashed line represents children who were not participating in sports at baseline, but started participating in the specific year (New participants). 

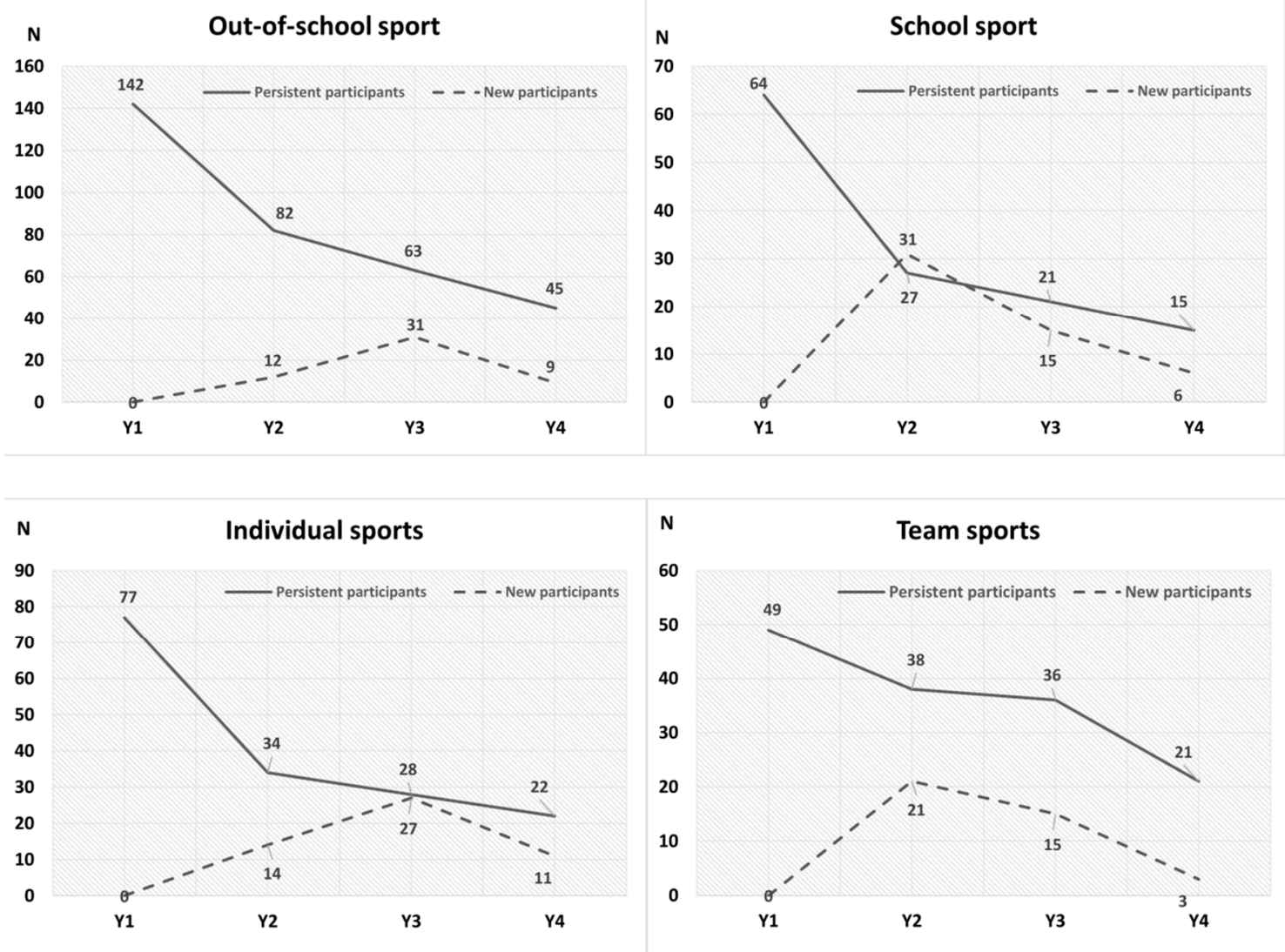

Figure 4. Persistence of sport participation over four years of high school in girls, stratified by school and out-of-school sport and by sport type (individual vs. team sports). The numbers show the frequency of children that participated in regular sport activities during a specific year. Solid line denotes participants who persistently participated in regular organized sport (Persistent participants) and dashed line represents children who were not participating in sports at baseline, but started participating in the specific year (New participants).

Table 4. Persistence of sport participation throughout four years of high school, stratified by school and out-of-school sport and by sport type (individual vs. team sports). The numbers indicate the frequency of participants that continued participating in sports (persistent participants) or started participating (new participants) in a specific year.

\begin{tabular}{ccccc}
\hline Study Variables & \multicolumn{2}{c}{ Boys } & \multicolumn{2}{c}{ Girls } \\
\hline & $\begin{array}{c}\text { Persistent } \\
\text { Participants }\end{array}$ & New Participants & $\begin{array}{c}\text { Persistent } \\
\text { Participants }\end{array}$ & New Participants \\
\hline N & N & N & N \\
\hline Out-of-school sport & & & & \\
\hline Baseline & 233 & $/$ & 142 & $/$ \\
Year 2 & 156 & 25 & 82 & 31 \\
Year 3 & 128 & 28 & 63 & 9 \\
Year 4 & 96 & 21 & 45 & $/$ \\
School sport & & & & 31 \\
\hline Baseline & 96 & $/$ & 64 & 15 \\
Year 2 & 52 & 44 & 27 & 6 \\
Year 3 & 53 & 39 & 21 & 15 \\
Year 4 & 50 & 24 & & \\
\hline
\end{tabular}


Table 4. Cont.

\begin{tabular}{ccccc}
\hline Study Variables & \multicolumn{2}{c}{ Boys } & \multicolumn{2}{c}{ Girls } \\
\hline & $\begin{array}{c}\text { Persistent } \\
\text { Participants }\end{array}$ & New Participants & $\begin{array}{c}\text { Persistent } \\
\text { Participants }\end{array}$ & New Participants \\
\hline Individual sports & & $\mathbf{N}$ & $\mathbf{N}$ & $\mathbf{N}$ \\
\hline Baseline & 133 & & & \\
Year 2 & 71 & $/$ & 77 & $/$ \\
Year 3 & 57 & 32 & 34 & 14 \\
Year 4 & 40 & 23 & 28 & 11 \\
Team sports & & 17 & 22 & $/$ \\
\hline Baseline & 119 & & & 21 \\
Year 2 & 71 & $/$ & 38 & 15 \\
Year 3 & 74 & 36 & 36 & 3 \\
Year 4 & 58 & 23 & 21 & \\
\hline
\end{tabular}

\section{Discussion}

The main goal of the present study was to investigate the extent of tracking of PA, SP, and SBs during four years of high school education. The main results of the study include: (a) PA showed moderate tracking across all intensities, while the tracking of SB was slightly higher, and could be interpreted as moderate to high; (b) the least active adolescents and those who spent the most time in front of the screens at year 1 were 12 and 15 times more likely to remain inactive and of exhibiting high screen time over four years of follow-up compared to their more active peers, respectively; (c) youth who participated in sport in school and outside of school at baseline were 16 to 28 times more likely to participate in sports throughout high school compared to children who were not involved in organized sport at the beginning of high school.

Like in this study, two previous studies among adolescents have also shown moderate tracking of PA [25,26]. However, Raustorp et al. [26] showed non-significant tracking coefficients for girls, while significant tracking coefficients for both boys and girls in the study by Aarnio et al. [25] were observed. As highlighted by Telama [19], of many factors influencing the value of tracking coefficients, the follow-up time, assessment method, gender, age, and the type of PA were the most important. Specifically, tracking coefficients were lower in girls compared with boys [19]. Possible reasons were a lower participation rate and major lifestyle transitions (schooling, obligations), which can also decrease tracking over a longer period of time [19]. In this study, we used a questionnaire to assess PA. The reasonably large measurement error related to PA assessment by questionnaires could lead to an underestimation of stability coefficients. In general, earlier studies have documented similar tracking regardless of the PA assessment method employed, pointing out that although objective methods measure PA more accurately, their ability to rank individuals and estimate tracking is not much superior to questionnaires [19].

Next, the stability coefficients for SB noted in this study indicate moderate to high tracking in both genders. This is in line with previous studies that aimed to track SB in similar age groups [27-29]. In general, moderate tracking of television viewing (TV), electronic games and/or computer use, and total screen time (ST) was observed, while the coefficients for TSB were notably smaller [27]. Tracking of SB generally shows similar patterns to tracking of PA, that is, an inverse association between the magnitude of tracking and the duration of follow-up [19].

A recent systematic review by Telama [19] noted that low activity or inactivity usually tracked better than activity. In the present study, however, both inactivity and high activity tracked well. To that end, inactive children should be identified at the beginning of high school and specifically targeted in order to prevent them remaining inactive. Conversely, good tracking of high activity levels 
indicates that the increase in PA induced by interventions timed at the beginning of high school could be preserved throughout adolescence. Although interventions aiming to promote PA and reduce SB in adolescents have shown a relatively small effect to date, school environment was highlighted as the most potent setting for behavioral interventions $[30,31]$. Thus, the first year of high school should serve as a period for both the detection of physically inactive individuals, as well as for the introduction of PA interventions.

The current study documented a marked decline in sport participation over four years of high school. We also noted that participants who were not engaged in sporting activities at the beginning of high school are highly unlikely to start participating in sports later on. Moreover, it has been previously shown that sports participation could extend well beyond adolescence, as participants that engaged in club sports in adolescence were shown to be two times more likely to continue participating in sports after 14 years of follow-up [32]. Poor PA promotion has been highlighted as a major reason for drop-out from organized sport [33]. Thus, school policies that promote organized sport participation before and during high school are warranted. This was also the first study that contrasted the tracking of participation in team and individual sports in the adolescent period. A prior study in Finland has shown that, among teenage boys, participation in team sports leads to high or very high PA levels in adulthood, whereas in females, such an effect is provided by individual sports [34]. In line with that, we observed that tracking was stronger for team sports in boys, and for individual sports among girls.

This study has several strengths. First, we included a fairly large number of participants $(\mathrm{N}=844)$. Second, we randomly selected schools, thus minimizing sample bias. Third, we followed our participants for all four years of high school, which was longer than the follow-up period in most of the previous studies among adolescents, particularly the ones examining SB activities. Fourth, unlike prior studies, we extended SB beyond screen time by including several other domains of sedentary time. Fifth, we succeeded in achieving a very low drop-out rate after four years of follow-up ( $N=721 / 844$; drop-out rate $=16 \%$ ). Finally, we assessed both PA and SB simultaneously, which enabled us to directly compare the extent of tracking of these two behaviors.

However, this study also has several limitations worth addressing. The main limitation of the present study was the use of questionnaires to assess PA and SB, which typically leads to an overestimation of PA and underestimation of SB activities [35]. Although this could have led to an underestimation of stability coefficients derived from GEE, it had a negligible effect on risk behavior tracking which is based on ranking individuals. Next, although all four waves of assessments were performed during the same season (i.e., spring), it is possible that PA varied because of different weather conditions within and between the years. However, we took care that the measurements at a specific school were performed at approximately the same date across all four waves of assessment. In addition to this, we compared average daily maximal temperatures and the amount of rainfall during a specific month at each of the four waves of assessment and found no significant differences (data not shown; $p=0.06-0.64$ ).

\section{Conclusions}

Moderate to strong tracking of both PA and SB between 15 and 18 years observed in this study was somewhat higher than previously reported for the similar period [14]. The fact that both low PA and high screen time tracked well indicates that the detection of these risk behaviors in the first grade of high school should be advocated. At the same time, the strong tracking of high PA and low screen time points to the fact that an increase in PA induced by interventions timed at the beginning of high school could probably be maintained at least to the end of adolescence. However, previous studies aiming to increase the level of PA in secondary-school children have only shown a small effect $[24,25]$. On the other hand, studies aiming to increase the level of PA in primary-school children have shown somewhat larger effect sizes for time spent in MVPA [36,37] and VPA [37] in an intervention group, compared to the control group. All this, along with the fact that both positive and risky behaviors related to energy expenditure remained stable throughout high school in this study, indicates that 
it might be more advisable to intervene at the primary school level. However, this remains to be confirmed by experimental evidence. Lastly, we noted that more than half of the participants that were engaged in organized sports in first grade had quit sports by the end of high school and that adolescents who were not engaged in sports at the beginning of high school were highly unlikely to start participating in sports later on. Thus, school policies that promote organized sport participation both before and during high school are warranted. Future studies should use objective methods in order to decrease the measurement error in assessing PA and SB.

Author Contributions: Conceptualization, M.M.-D. and M.S.; Methodology, M.M.-D. and M.S.; Software,

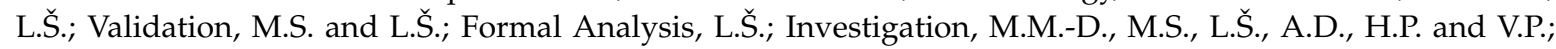
Resources, M.M.-D. and M.S.; Data Curation, M.S. and L.Š.; Writing-Original Draft Preparation, M.S. and L.S.; Writing-Review \& Editing, M.M.-D., M.S., L.ك̌., A.D., H.P. and V.P.; Visualization, M.S. and L.Š.; Supervision, M.S.; Project Administration, M.M.-D. and M.S.; Funding Acquisition, M.M.-D.

Funding: This investigation is a part of the Croatian Physical Activity in Adolescence Longitudinal Study (CRO-PALS), funded by the Croatian Science Foundation under the number IP-06-2016-9926.

Acknowledgments: We would like all the students and teachers for their enthusiastic participation in the study. The raw data used to support the findings of this study are available from the corresponding author upon request.

Conflicts of Interest: The authors declare no conflicts of interest.

\section{Abbreviations}

$\begin{array}{ll}\text { BMI } & \text { Body-mass index } \\ \text { CRO-PALS } & \text { Croatian Physical Activity in Adolescence Longitudinal Study } \\ \text { GEE } & \text { Generalized estimating equations } \\ \text { MET } & \text { Metabolic equivalent } \\ \text { MPA } & \text { Moderate physical activity } \\ \text { MVPA } & \text { Moderate to vigorous physical activity } \\ \text { OR } & \text { Odd ratio } \\ \text { PA } & \text { Physical activity } \\ \text { PAEE } & \text { Physical activity energy expenditure } \\ \text { SB } & \text { Sedentary behavior } \\ \text { SHAPES } & \text { School Health Action, Planning and Evaluation System questionnaire } \\ \text { SP } & \text { Sport participation } \\ \text { SPSS } & \text { Statistical Package for Social Sciences } \\ \text { ST } & \text { Screen-time } \\ \text { S4SF } & \text { Sum of four skinfolds } \\ \text { TSB } & \text { Total sedentary behavior } \\ \text { TV } & \text { Television viewing } \\ \text { VPA } & \text { Vigorous physical activity } \\ \text { 95\% CI } & \text { 95 percent confident interval }\end{array}$

\section{References}

1. World Health Organization. Global Recommendations for Physical Activity and Health; WHO Press: Geneva, Switzerland, 2010.

2. Katzmarzyk, P.T.; Church, T.S.; Craig, C.L.; Bouchard, C. Sitting time and mortality from all causes, cardiovascular disease, and cancer. Med. Sci. Sports Exerc. 2009, 41, 998-1005. [CrossRef] [PubMed]

3. Janssen, I.; LeBlanc, A.G. Systematic review of the health benefits of physical activity and fitness in school-aged children and youth. Int. J. Behav. Nutr. Phys. Act. 2010, 7, 40. [CrossRef] [PubMed]

4. Tremblay, M.S.; LeBlanc, A.G.; Kho, M.E.; Saunders, T.J.; Larouche, R.; Colley, R.C.; Goldfield, G.; Connor Gorber, S. Systematic review of sedentary behaviour and health indicators in school-aged children and youth. Int. J. Behav. Nutr. Phys. Act. 2011, 8, 98. [CrossRef] [PubMed]

5. WHO. Global School-Based Student Health Survey. 2011. Available online: http://www.who.int/chp/gshs/ en/ (accessed on 15 August 2018). 
6. Nelson, M.C.; Neumark-Stzainer, D.; Hannan, P.J.; Sirard, J.R.; Story, M. Longitudinal and secular trends in physical activity and sedentary behavior during adolescence. Pediatrics 2006, 118, 1627-1634. [CrossRef] [PubMed]

7. Rauner, A.; Jekauc, D.; Mess, F.; Schmidt, S.; Woll, A. Tracking physical activity in different settings from late childhood to early adulthood in Germany: The MoMo longitudinal study. BMC Public Health 2015, 15, 391. [CrossRef] [PubMed]

8. Janssen, X.; Mann, K.D.; Basterfield, L.; Parkinson, K.N.; Pearce, M.S.; Reilly, J.K.; Adamson, A.J.; Reilly, J.J. Development of sedentary behavior across childhood and adolescence: Longitudinal analysis of the Gateshead Millennium Study. Int. J. Behav. Nutr. Phys. Act. 2016, 13, 88. [CrossRef] [PubMed]

9. Melkevik, O.; Torsheim, T.; Iannotti, R.J.; Wold, B. Is spending time in screen-based sedentary behaviors associated with less physical activity: A cross national investigation. Int. J. Behav. Nutr. Phys. Act. 2010, 7, 46. [CrossRef] [PubMed]

10. Howley, E.T. Type of activity: Resistance, aerobic and leisure versus occupational physical activity. Med. Sci. Sports Exerc. 2001, 33, 364-369. [CrossRef]

11. Eime, R.; Harvey, J.; Sawyer, N.; Craike, M.; Symons, C.; Polman, R.; Payne, W. Understanding the contexts of adolescent female participation in sport and physical activity. Res. Q. Exerc. Sport 2013, 84, 157-166. [CrossRef] [PubMed]

12. Mäkelä, S.; Aaltonen, S.; Korhonen, T.; Rose, R.J.; Kaprio, J. Diversity of leisure-time sport activities in adolescence as a predictor of leisure-time physical activity in adulthood. Scand. J. Med. Sci. Sports 2017, 27, 1902-1912. [CrossRef] [PubMed]

13. Zimmermann-Sloutskis, D.; Wanner, M.; Zimmermann, E.; Martin, B. Physical activity levels and determinants of change in young adults: A longitudinal panel study. Int. J. Behav. Nutr. Phys. Act. 2010, 7, 2-10. [CrossRef] [PubMed]

14. Department of Health and Ageing. Australian National Children's Nutrition and Physical Activity Survey: Main Findings, 2008; Department of Health and Ageing: Canberra, Australia, 2007.

15. Eime, R.M.; Casey, M.M.; Harvey, J.T.; Sawyer, N.A.; Symons, C.M.; Payne, W.R. Socioecological factors potentially associated with participation in physical activity and sport: A longitudinal study of adolescent girls. J. Sci. Med. Sport 2015, 18, 684-690. [CrossRef] [PubMed]

16. Eime, R.; Payne, W.; Casey, M.; Harvey, J. Transition in participation in sport and unstructured physical activity for rural living adolescent girls. Health Educ. Res. 2010, 25, 282-293. [CrossRef] [PubMed]

17. Malina, R.M. Tracking physical activity across the life span. Res. Q. Exerc. Sport 1996, 67, 48-57. [CrossRef]

18. Foulkes, M.A.; Davis, C.E. An index of tracking for longitudinal data. Biometrics 1981, 37, 439-446. [CrossRef]

19. Telama, R. Tracking of physical activity from childhood to adulthood: A review. Obes. Facts 2009, 2, 187-195. [CrossRef] [PubMed]

20. Biddle, S.J.H.; Pearson, N.; Ross, G.M.; Braithwaite, R. Tracking of sedentary behaviours of young people: A systematic review. Prev. Med. 2010, 51, 345-351. [CrossRef] [PubMed]

21. Trang, N.H.; Hong, T.K.; Van Der Ploeg, H.P.; Hardy, L.L.; Kelly, P.J.; Dibley, M.J. Longitudinal sedentary behavior changes in adolescents in Ho Chi Minh City. Am. J. Prev. Med. 2013, 44, 223-230. [CrossRef] [PubMed]

22. Štefan, L.; Sorić, M.; Devrnja, A.; Podnar, H.; Mišigoj-Duraković, M. Is school type associated with objectively measured physical activity in 15-year-olds? Int. J. Environ. Res. Public Health 2017, 14, 1417. [CrossRef] [PubMed]

23. Wong, S.L.; Leatherdale, S.T.; Manske, S.R. Reliability and validity of a school-based physical activity questionnaire. Med. Sci. Sports Exerc. 2006, 38, 1593-1600. [CrossRef] [PubMed]

24. Twisk, J.W.R. Applied Longitudinal Data Analysis for Epidemiology. A Practical Guide; Cambridge University Press: New York, NY, USA; Cambridge, UK, 2003.

25. Aarnio, M.; Winter, P.; Peltonen, J.; Kujala, U.M.; Kaprio, J. Stability of leisure-time physical activity during adolescence-A longitudinal study among 16-, 17- and 18-year-old Finnish youth. Scan. J. Med. Sci. Sports 2002, 12, 179-185. [CrossRef]

26. Raustorp, A.; Svenson, K.; Perlinger, T. Tracking of pedometer-determined physical activity: A 5-year follow-up study of adolescents in Sweden. Pediatr. Exerc. Sci. 2007, 19, 228-238. [CrossRef] [PubMed] 
27. Baggett, C.D.; Stevens, J.; McMurray, R.G.; Evenson, K.R.; Murray, D.M.; Catellier, D.J.; He, K. Tracking of physical activity and inactivity in middle school girls. Med. Sci. Sports Exerc. 2008, 40, 1916-1922. [CrossRef] [PubMed]

28. Berkey, C.S.; Rockett, H.R.H.; Gillman, M.W.; Colditz, G.A. One-year changes inactivity and in inactivity among 10- to 15-year-old boys and girls: Relationship to change in body mass index. Pediatrics 2003, 111, 836-843. [CrossRef] [PubMed]

29. Motl, R.W.; Mcauley, E.; Birnbaum, A.S.; Lytle, L.A. Naturally occurring changes in time spent watching television are inversely related to frequency of physical activity during early adolescence. J. Adolesc. 2006, 29, 19-32. [CrossRef] [PubMed]

30. Morton, K.L.; Atkin, A.J.; Corder, K.; Suhrcke, M.; van Sluijs, E.M. The school environment and adolescent physical activity and sedentary behaviour: A mixed-studies systematic review. Obes. Rev. 2016, 17, 142-158. [CrossRef] [PubMed]

31. Hynynen, S.T.; van Stralen, M.M.; Sniehotta, F.F.; Araújo-Soares, V.; Hardeman, W.; Chinapaw, M.J.M.; Vasankari, T.; Hankonen, N. A systematic review of school-based interventions targeting physical activity and sedentary behaviour among older adolescents. Int. Rev. Sport Exerc. Psychol. 2016, 9, 22-44. [CrossRef] [PubMed]

32. Richards, R.; Williams, S.; Poulton, R.; Reeder, A.L. Tracking club sport participation from childhood to early adulthood. Res. Q. Exerc. Sport 2007, 78, 413-419. [CrossRef] [PubMed]

33. Marques, A.; Martins, J.; Santos, F.; Sarmento, H.; Carreiro da Costa, F. Correlates of school sport participation: A cross-sectional study in urban Portuguese students. Sci. Sports 2014, 29, 31-38. [CrossRef]

34. Tammelin, T.; Näyhä, S.; Hills, A.P.; Järvelin, M.R. Adolescent participation in sports and adult physical activity. Am. J. Prev. Med. 2003, 24, 22-28. [CrossRef]

35. Gillison, F.B.; Standage, M.; Skevington, S.M. Relationship among adolescents' weight perceptions, exercise goals, exercise motivation, quality of life and leisure-time exercise behaviour: A self-determination theory approach. Health Educ. Res. 2006, 21, 836-847. [CrossRef] [PubMed]

36. Engelen, P.; Bundy, A.C.; Naughton, G.; Simpson, J.M.; Bauman, A.; Ragen, J.; Baur, L.; Wyver, S.; Tranter, P.; Niehues, A.; et al. Increasing physical activity in young primary school children-It's child's play: A cluster randomized controlled trial. Prev. Med. 2013, 56, 319-325. [CrossRef] [PubMed]

37. Powell, E.; Woodfield, L.A.; Nevill, A.M. Increasing physical activity levels in primary school physical education: The SHARP principles models. Prev. Med. Rep. 2016, 3, 7-13. [CrossRef] [PubMed] 